in later life. This method of defence would not be 'so effectual upon the surface of the ground where its enemy could attack it from any source instead of directly behind or before, because with its unwieldy body it would not be able to eject the substance ln any desired direction suddenly. This, then, appears to be a habit acquired by the insect since it has taken to its underground life; for it is hardly probable that it would be provided both with the habit of making long leaps to escape from its enemies, and at the same time to eject in large quantities this protective fluid.

There are some rather serious objections to this theory of changed conditions and habits. First may be mentioned the unusual development of the tarsus, fitting it for its underground life and burrowing propensities; but it is not unreasonable to suppose that the front legs were developed gradually in conformity with its changing habits. And it is perhaps true that if the insect lived upon the ground, it occasionally burrowed for roots, or for shelter, and originally had an unusual development of the tarsus. Its carnivorous habits may have been acquired in consesequence of its frequent contact with earth-worms, when other food was scarce, as there are many other insects which normally feed upon vegetable food, that will resort to animal food, devouring even their own kind, as in the mole cricket, when pressed by hunger.

Second, an observation made by Westwood and others in Europe upon $G$. vulgaris would seem to weaken my argument regarding the development of the insect. It is stated that the larvæ of the European species, before the first moult, live together in one burrow, with the mother cricket, but scatter after this moult. I have seen the very young larvæ of our species only in confinement, and cannot say whether in the natural state they would scatter before this time or not. They run about in the breeding-cage more before the first moult than afterward. However, I think it probable that the mother cricket feeds the young, at this early stage, as she exercises great solicitude for them apparently, in other matters, or in time of danger. I have several times seen the mother take the young in her mouth when disturbed, as a cat does her kitten, and carry them to places of safety. She will also carry her eggs to a new burrow when they have been discovered, as I have several times observed. Hence it seems probable the young larvæ live together under the protection of the mother cricket, and would have but little need of a protective ejection. But the jumping habit which is chiefly useful in escaping from their enemies, being confined only to the early larval stage, presents a stronger argument for changed conditions. I may say, however, that neither of these are presented as conclusive arguments but rather mere suppositions or suggestions, to be followed up by other observations.

\section{THE SCIENCE OF SMELLING.}

BY PBof. DE volson wood, stevens INSTitute, hoboKen, N. J.

THE greater part of the science of seeing is contained in the science of optics, and this is founded upon the theory of undulations of the ether and the way in which they are modified by the media through which they pass. The form of the surface, whether plane or curved, as well as the density of the medium produces marked effects.

Similarly, the greater part of the science of hearing is contained in the science of acoustics, and this also treats of undulations, or waves propagated in air or other gases. It is not believed in either case that solid particles pass from a source to the sensitive nerves to produce the particular sensation.

Why should there not be a science of smelling? The principal part of such a science would consist of an investigation of the mechanical properties of odors, and might briefly be called " Odorology." Is it not highly probable that odors are also propagated by undulations of an ether? And zet we are familiar with the statements made by writers, such as "A grain of musk wil keep a room scented for many years. During the whole of the time it must be slowly evaporating, giving out its particles to the currents of air to be wafted presently out of doors; yet in all this time the musk seems to lose but little of its weight." "The acute sense of smell of the dog is well known; for he can detect the track of his master long after the tracks have been made, which shows that some slight characteristic matter is left at each footfall."

Those who thus speak impart the idea that odor is material. I prefer to think of it as a property of matter, which produces its own peculiar undulations; and that the sensation of odor is produced by these undulations in the olfactories. Musk retains this property for a very long time, while some bodies lose it rapidly. The man may leave some characteristic matter on the ground at each footstep, but it is not necessary that particles of that matter shall pass from the ground into the nose of the dog in order that he may track his master. It is only necessary that that matter shall possess the property of sending forth certain undulations. Indeed, it is not difficult to conceive that the ground itself has imparted to it the property of sending forth the desired undulations.

These facts being assumed, investigations might be made to determine the velocity with which odors are propagated, and whether they are subject to reflection, refraction, and interference, and other properties common to sound and light; also whether the different odors are due to different wave-lengths, and if the strength and intensity of the odor is due to the amplitude of the wave, as in light and sound. The physiological qualities of the olfactories by which they enable one to detect odors of different qualities and intensities furnish a field for the most delicate and refined investigation.

\section{NOTES AND NEWS.}

Persons who are very susceptible to the effects of gnat-bites state that the irritation seems to return on the third day, and in those who have exceptionally sensitive skins again on the sixth day. Thus the effects of gnat-bites, or rather of the poison which they instil into our blood, bave a certain ana logy with the symptoms of intermittent fever. This need, perhaps, scarcely surprise us if we recollect from what materials the juices of the gnat have been elaborated.

- Herbert M. Thompson's “ The Theory of Wages and its Application to the Eight-Hours Question," published by Macmillan $\&$ Co., is a timely contribution to the discussion of this vital question of the present industrial crisis.

- Lovers of birds and flowers will delight in Miss Yonge's new book announced by Macmillan \& Co. Under the title of "An Old Woman's Outlook" she describes out-door life in England as she has watched it for so many years. The chapters are so arranged that each shall cover its special month.

- "Round London, Down-East, and Up-West" is the self-explaining title of a new book by Montagu Williams, barrister, author of "Leaves From a Life," etc. It will be issued by the Macmillans.

-D. Appleton \& Co. will shortly add to their list of Good Books for Young Readers " Along the Florida Reef," by C. F. Holder, which is a story of camping and fishing adventures in company with a naturalist in Florida. The author combines entertainment and instruction, and his book is filled with illustrations which will be prized by every young reader who has ever visited the seashore, or cares for information regarding fishes, shells, and the various forms of marine life. The same firm will publish immediately "The Story of Columbus," by Elizabeth Eggleston Seelye, edited by Dr. Edward Eggleston, with nearly a hundred illustrations by Allegra Eggleston. This book is the result of extensive in vestigations which have been carefully verified by Dr. Eggleston. While the book contains all the results of modern inquiry offered in the bulkiest biographies, the story is here condensed and the material selected with a view to an always interesting narrative. To a considerable extent the plan of both text and illustrations is like that of Eggleston's " Household History of the United States." "The Story of Columbus" will be the first volume in a series to be called Delights of History, which will be prepared by the same author, artist, and editor. 


\section{Science}

\section{THE SCIENCE OF SHELLING}

DE Volson Wood

Science ns-20 (506), 215

DOI: 10.1126/science.ns-20.506.215

ARTICLE TOOLS

PERMISSIONS http://science.sciencemag.org/content/ns-20/506/215.1.citation

http://www.sciencemag.org/help/reprints-and-permissions 